\title{
Medicalização da sociedade ou socialização da medicina? - reflexões em torno de um conceito
}

\author{
Medicine-oriented society or socialized \\ medicine? - considerations on a concept
}

\author{
Laurinda Rosa Maciel \\ Historiadora, Casa de Oswaldo Cruz \\ Rua Santa Cristina, 46/301 \\ 22245-398 Rio de Janeiro - RJ Brasil \\ laurinda@coc.fiocruz.br
}

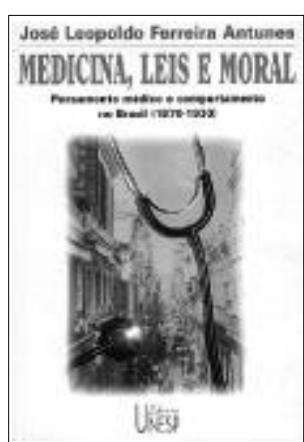

José Leopoldo Ferreira Antunes Medicina, leis e moral: pensamento médico e comportamento no Brasil (1870-1930) São Paulo, Fundação Editora da Unesp, 1999, 304p.
$\mathrm{H}$ ouve, de fato, um processo de medicalização da sociedade brasileira? Ou o que aconteceu foi uma socialização da medicina? Se houve, como tal processo se deu? Essas são as questões que José Leopoldo procura analisar em seu livro, levando-se em consideração a forma trabalhada por outros autores na investigação desse processo, tais como Jurandir Freire Costa, em Ordem médica e norma familiar, e Roberto Machado et alii de Danação da norma. Qual o papel da medicina legal nessa trajetória?

O livro é dividido em seis capítulos, nos quais se procurou analisar como o pensamento médico foi direcionado para objetos da vida social, tais como o crime, o sexo e a morte. $\mathrm{O}$ corte cronológico escolhido para análise e consideração pelo autor foi o período da Belle Époque, por possuir ampla e criteriosa reflexão científica sobre tais temas na literatura médica, tendo os médicos nesse momento feito da medicina uma 'ciência da moral'.

No primeiro capítulo - 'O pensamento médico entre a história, a sociologia e a medicina legal' —, José Leopoldo privilegia a análise sobre a gênese da medicina legal no Brasil e aponta o estudo de Flamínio Fávero, Evolução científica da medicina legal no Brasil, do ano de 1922, como o modelo seguido por toda uma geração, não esquecendo de citar Oscar Freire. Flamínio Fávero divide a medicina legal em três fases distintas, sendo que na última destas nomeia Nina Rodrigues como seu fundador no Brasil após 1881. Após as análises de Nina Rodrigues sobre as diferenças entre os indivíduos de raças distintas, suas idéias se tornam essenciais para a orientação médica nas formulações jurídicas. É interessante ressaltar aqui que o ano de 1881 é singular no que se refere à criação de novos campos de atuação e especialização da medicina, devido a uma grande reforma educacional nos cursos de nível superior da Corte. Assim, foram criadas novas cadeiras nos cursos de medicina, como, por exemplo, medicina legal, clínica psiquiátrica, clínica de crianças, dermatologia, partos etc.

Em 'Questões médico-legais no Brasil', sua opção de construção do capítulo é bastante atraente e instigante, dando conta da pesquisa minuciosa realizada nas fontes, o que torna o texto extremamente agradável. Apresentando uma série de casos que foram singulares no período 
proposto, o autor acredita que estes são mais do que exemplos da aplicação da medicina legal à realidade social. Além de serem reflexo dos debates gerados na disputa entre os especialistas, são também uma forma de se perceber como se deu a construção do pensamento médico aplicado aos temas e às questões morais. Algo como a afirmação da competência de um determinado saber médico e de sua especialização, ou seja, a construção de um campo científico, com as disputas e controvérsias presentes nesse universo, tal como analisado por Pierre Bourdieu.

São narrados brevemente casos como o de Custódio Alves Serrão, internado no Hospício Nacional de Alienados em 1896, que foge da instituição e gera um vigoroso debate entre médicos e juristas acerca de quem melhor poderia dele cuidar: o médico-psiquiatra ou o juiz de direito e advogado? Muitos outros casos importantes e representativos para a consolidação da medicina legal são narrados, abordando temas que vão desde a identificação de cadáveres como prova circunstancial de autos, a caracterização definitiva dos suicidas ou as perícias realizadas no hímen, que definiram e solidificaram melhor o campo de atuação dessa especialidade.

Nos três capítulos seguintes, 'Crime', 'Sexo' e 'Morte', aspectos como a responsabilidade civil de alienados ou alcoólatras, infância e crime, libertinagem e regulamentação da prostituição, importância da autópsia e atestado de óbito, são citados para que o leitor perceba como tais assuntos foram objeto de debates e confrontos entre pensadores como Juliano Moreira ou Nina Rodrigues, Renato Kehl ou Franco da Rocha, Souza Lima ou Afrânio Peixoto. Não só nas célebres sessões da Academia Nacional de Medicina, como também por meio de artigos, com réplicas e tréplicas, publicadas em revistas especializadas, procurando chamar atenção para a necessidade de uma maior especialização do campo da medicina, com suas inexoráveis especificidades.

José Leopoldo teme que, ao escolher casos que têm o crime, o sexo e a morte como fio condutor de uma análise, possa não agradar plenamente a algum médico legalista. No entanto, toda escolha implica inclusão e exclusão de temas que serão mais importantes do que aqueles que não os escolhidos. Isso é inerente ao trabalho de pesquisa, uma vez que as escolhas delimitadas e bastante recortadas têm também o objetivo de tornar o trabalho exeqüível. Por que deveria ele, afinal, escolher esses três temas? Qual sua relevância para a análise da constituição da medicina legal? Ao recuperar a medicina legal no período de 1870 a 1930, frisa que sua participação na história do pensamento social brasileiro dirigiu-se especificamente ao conhecimento e à intervenção sobre os fenômenos de ordem moral. Ele opta por uma análise a partir de grandes temas, de assuntos que foram matéria de intervenção médico-legal no país no período proposto, como estratégia para tecer um panorama da história da disciplina.

Ao falar da 'Humanização da medicina e medicalização da sociedade', o autor faz uma espécie de balanço das reivindicações médicas referentes ao crime, ao sexo e à morte, e de como tais reivindicações se deram na sociedade. O balanço fica um tanto pessimista, uma vez que, embora a obrigatoriedade de exame pré-nupcial, a regulamentação da prostituição ou a possibilidade de tornar-se crime a transmissão de doenças venéreas tenham sido reivindicações médicas no período, não sensibilizaram as autoridades a ponto de se transformarem em leis. Isso aponta para o que 
o autor chama não de uma 'medicalização da sociedade', mas uma 'socialização da medicina'. Nesse sentido, vale ressaltar que outras categorias profissionais que não a medicina tomaram para si a tarefa de esquadrinhar a moralidade social e refletir sobre a moral. A partir da década de 1930, a medicina começa a enfrentar a perda de um certo monopólio, tendo, por exemplo, nos variados meios de comunicação de massa ou na literatura valiosos veículos de disseminação de valores morais padronizados para a sociedade.

A medicina legal — que, segundo José Leopoldo, foi a especialidade médica no período abordado que mais se empenhou nessa formação moral da sociedade — vai abandonar seu papel controverso por natureza e seguir o "caminho da experimentação, a indicação metodológica proposta pela microbiologia para todos os ramos da atividade científica. Com isso, a medicina legal teria encontrado um novo ponto de equilíbrio nos sucessos dos laboratórios, na segurança das dosagens e titulações" (p. 278), abandonando o terreno da controvérsia e se alojando na calmaria dos incontestáveis procedimentos periciais.

Esses são alguns dos aspectos que o leitor terá em mãos, ao iniciar a leitura do livro - originalmente uma tese de doutoramento defendida no Departamento de Sociologia da Universidade de São Paulo (USP) em 1995 —, publicado em 1999, com algumas mudanças. Seu interesse pelo tema surgiu a partir da obra de Pierre Darmon, Médicos e assassinos na Belle Époque: a medicalização do crime, na qual o autor faz uma análise das teorias médicas sobre as características anatômicas e fisiológicas associadas à inclinação criminosa.

Em seu livro, José Leopoldo se propõe a recuperar o pensamento médico brasileiro aplicado às questões de moral como estratégia para evidenciar as condições que possibilitaram a emergência do conceito de medicalização. Tal conceito, segundo ele, precisa ser mais bem explorado, no sentido de se fazer uma arqueologia do termo e de seu real significado empregado nos estudos médicos. A meu ver, o processo de medicalização se dá pela via da norma e não da lei, uma vez que a sociedade pode estar medicalizada por meio desta e ainda assim não se respeitá-la. Sua concretização ocorre por meio da norma, que não necessariamente precisa da existência de leis para regulá-la.

José Leopoldo acaba por assumir o conceito de medicalização pensado pelos autores de Da(n)ação da norma, apesar de em dado momento criticar seu uso. Penso que ele não convence quando faz essa crítica justamente por sua narrativa espelhar algo parecido, como se os médicos fossem um bloco homogêneo, articulado e uníssono, em torno de um ideal: medicalizar uma sociedade 'doente', necessitada de uma intervenção que só a medicina seria capaz de fornecer. É preciso parar e pensar quem são os que propõem essas mudanças e que 'doenças' são essas patologizadas pelo olhar médico. Na tentativa de reinventar o conceito, o autor acaba trabalhando com o mesmo sentido que critica. Apesar de propor uma nova visão deste, que seria o definido por ele como uma "arqueologia do termo e de seu real e verdadeiro significado empregado, sobretudo o utilizado nos estudos médicos", José Leopoldo acaba por repetir a mesma fórmula de Jurandir Freire Costa e dos autores de $\operatorname{Da}(n)$ ação da norma. 
Uma atenção especial deve ser dada às fontes com as quais trabalha. Elas são inúmeras, e algumas merecem ser citadas, como, por exemplo, literatura e imprensa especializada, atas de reuniões científicas e de associações profissionais, periódicos etc., cuja diversidade vem enriquecer sua análise, tornando-a fluida, densa mas agradável, ao mesmo tempo. $\mathrm{O}$ período escolhido para análise em seu trabalho foi bastante privilegiado na intervenção médica sobre a moral, razão pela qual ele consegue arrolar e trabalhar criticamente essa diversidade de massa documental. Seu trabalho de pesquisa é bastante minucioso e aponta para o valor do material que um pesquisador terá em mãos: cerca de $80 \%$ dos autores citados nas referências bibliográficas são de fontes primárias, e Nina Rodrigues, Afrânio Peixoto e Souza Lima são os que mais aparecem com seus artigos em periódicos.

Uma das mudanças efetuadas pelo autor para concretizar a publicação da tese sob a forma de um livro foi a supressão das notas de pé de página, o que acaba comprometendo o entendimento da leitura em algumas passagens. Sabemos que é bastante complicado tentar inserir no próprio texto as explicações que, por vezes, encontram-se nas notas de rodapé. Se por um lado isso facilita a leitura e a torna mais solta, por outro, algumas explicações adicionais normalmente encontradas nas notas fazem falta em determinadas passagens. Com relação à bibliografia usada, José Leopoldo não foi muito benevolente com o autor Michel Foucault, já que sua presença nesse item só se faz uma vez. No meu entender, é bastante complicado tentar trabalhar com a questão da soberania e disciplina apenas pelos textos de Microfísica do poder. Como tratar de tais questões sem citar, por exemplo, Vigiar e punir? Foucault merecia estar mais presente na obra, pois ficaram faltando as referências básicas quando normalmente se analisa a medicalização pela via da disciplina. Ao propor uma arqueologia do termo medicalização, o autor não recorre a Foucault para enriquecer seu trabalho.

Seria interessante saber quando foi feita a atualização das referências bibliográficas, pois sabemos que, embora o livro tenha sido editado em 1999, não faz menção a alguns estudos publicados e/ou defendidos até aquele período, como, por exemplo, os de Ângela Pôrto, Jayme Benchimol, Gilberto Hochman, Magali Engel e Nísia Trindade, para citar alguns. Todos são importantes estudos desenvolvidos à luz de uma nova ótica de análise, que busca romper com uma visão um tanto simplista do poder médico ou da medicalização, fazendo supor que tais mecanismos são bastante mais complexos.

Ainda no que se refere às referências bibliográficas, é importante ressaltar que ficaria mais atraente para o pesquisador interessado em beber naquelas mesmas fontes uma organização diferente da que foi dada na edição do livro. Há certa confusão nesse item, no que se refere à disposição escolhida para a versão final do livro. As referências encontramse no mesmo espaço: fontes primárias de qualquer natureza (como as teses da Academia Imperial e Nacional de Medicina), artigos de periódicos, pareceres médico-legais, obras publicadas - algumas já bastante conhecidas - etc. Estão dispostas no mesmo item, apenas separadas por ordem alfabética de autor. O leitor, por vezes, fica confuso no momento em que tenta procurar uma referência mais específica e que interessa diretamente ao seu campo de atuação. 
Relembrando o início do livro, José Leopoldo afirma que a contribuição de seu estudo e de toda a sua pesquisa teria um peso diferenciado para cada categoria profissional, a saber, historiadores, médico-legistas e sociólogos. No que se refere aos historiadores, sua ajuda seria a localização e análise de fontes documentais de variados tipos, oferecendo a eles a possibilidade de outros estudos. Penso que essa contribuição, por si só, já seria grande o bastante por lançar sementes para a problematização de algumas questões que os escritos médicos podem nos dar, e ele nos trouxe uma outra maneira de pensar a medicalização da sociedade: por intermédio da atuação de uma determinada categoria médica e sua influência nos limites da moral.

Ele aponta para uma resposta ao nosso questionamento presente no título: para além de uma 'socialização da medicina', talvez o ideal fosse chamar esse processo de 'humanização da medicina', "para sublinhar sua conversão aos temas e aos procedimentos das ciências humanas" (p. 275), no sentido de promover ainda mais a interação do saber médico com os fatos sociais.

\section{REFERÊENCIAS BIBLIOGRÁFICAS}

Benchimol, Jayme Larry Do Pasteur dos micróbios ao Pasteur dos mosquitos: febre amarela no 1996

Rio de Janeiro (1880-1903). Tese de doutoramento, Niteró́, Instituto de Ciências Humanas e Filosofia, Universidade Federal Fluminense.

Costa, Jurandir Freire 1989

Darmon, Pierre 1991

Engel, Magali 1995

Foucault, Michel 1986

Foucault, Michel 1981

Harris, Ruth 1993

Hochman, Gilberto 1998

Lima, Nísia Trindade 1999

Machado, Roberto; Loureiro, Ângela; Luz, Rogério e Muricy, Kátia 1978
Ordem médica e norma familiar.

Rio de Janeiro, Graal.

Médicos e assassinos na Belle Époque: a medicalização do crime.

São Paulo, Paz e Terra.

A loucura na cidade do Rio de Janeiro: idéias e vivências (1830-1930).

Tese de doutoramento, Campinas, Instituto de Filosofia e Ciências Humanas, Universidade Estadual de Campinas.

Vigiar e punir: história da violência nas prisões.

Petrópolis, Vozes.

Microfísica do poder.

Rio de Janeiro, Graal.

Assassinato e loucura: medicina, leis e sociedade no fin de siècle.

Rio de Janeiro, Rocco.

A era do saneamento: as bases da política de saúde pública no Brasil.

São Paulo, Hucitec/Anpocs.

Um sertão chamado Brasil: intelectuais e representação geográfica da identidade nacional. Rio de Janeiro, Iuperj/Ucam.

Da(n)ação da norma: medicina social e constituição da psiquiatria no Brasil. Rio de Janeiro, Graal. 